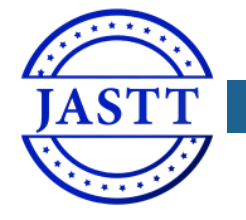

\title{
Research Trends on Machine Learning in Construction Management: A Scientometric Analysis
}

\author{
Nguyen Van Tam, Nguyen Quoc Toan* \\ Faculty of Construction Economics and Management, Hanoi University of Civil Engineering, Vietnam, \\ (tamnv2,toannq)@nuce.edu.vn \\ *Correspondence: toannq@nuce.edu.vn
}

\begin{abstract}
Machine learning plays a vital role in construction industry which could make improve project's safety, productivity, and quality. Many studies have attempted to explore the potential opportunities to adopt this technology in different aspects of the construction sector. However, no comprehensive study to review the global research trends on this technological advancement in construction management domain. The goal is to investigate and summarize the state-of-the-art knowledge body in this topic in a systematic manner. To achieve this, this paper considered 161 studies on machine learning in construction management related to bibliographic records retrieved from the Scopus database by adopting scientometric analysis approach. This paper found that since 2014, there has been a considerable increase in the number of publications on this domain. Researchers from the United States, China, and Australia have been the main contributors to this research area through regional analysis. This study also revealed that approximately $34 \%$ of all countries in the world are engaged in this domain research. In addition, five main aspects in construction management have been applied machine learning techniques, namely, assess and reduce risk, safety management for construction sites, cost estimation and prediction, Schedule management, and building energy demand prediction. Furthermore, three potential construction management research areas that can apply this technology were proposed for further studies. The findings will help both professionals and researchers more understanding how machine learning knowledge is evolving and its role played in the construction management domain, and this study thus offers a useful reference point to how can develop this area in the future.
\end{abstract}

Keywords: Machine Learning, Construction Management, Scientometric

Received: August $7^{\text {th }}, 2021$ / Accepted: September $8^{\text {th }}, 2021$ / Online: September $9^{\text {th }}, 2021$

\section{INTRODUCTION}

Since the construction industry has not made as many technological advancements as other industries (i.e., finance, entertainment, healthcare, and education) [1], things have become increasingly difficult for its labor. However, finding the means to introduce emerging technology while keeping on track with construction projects is challenging. Machine learning has the potential to move the industry forward by continuously enhancing things for employees, contractors, clients, and other project stakeholders. Several companies in these sectors are constantly looking for new ways to use technology to stay ahead of the competition and remain profitable. However, construction industry productivity is uncertain, if not deteriorating, due to a lack of technological investment, which is a contributing factor [2-5]. Even though new computers, software, servers, and networks are all important components of technical development, construction digitization goes beyond that [1]. The rise in machine learning algorithms may be due in part to the exponential growth in the development and internet of things adoption [6].

Although machine learning in construction could seem like a distant idea decades away from being a reality, this technology's future is closer. Machine learning has been gaining popularity in the construction industry in recent years [7]. This technology is are making changes across construction project management, including assess and reduce risk, safety management for construction sites, cost estimation and prediction, schedule management, and building energy demand prediction. Academic research papers published related to the adoption of machine 
learning in the construction management area are necessary to both professionals and researchers. However, the research topic in relation to construction project management is highly diversified; there is a lack of comprehensive literature review in this area. Further studies will benefit from the integration and classification of published literature reviews within the machine learning in construction management domain because it will enable them to gain a better understanding of the subject and perform related research more intensively and efficiently. Hence, it is critical to summarize the global trends of machine learning in construction management through comprehensive analysis and to propose new research directions. In this regard, this paper performs a systematic analysis of studies on machine learning in construction management with the following derived objectives:

- To ascertain the annual publication trends of machine learning in construction management

- To identify countries with the most published papers on machine learning in construction management

- To identify active contributors in studying machine learning in construction management

- To summarize, compare, and contrast the key findings of machine learning in construction management studies.

\section{LITERATURE REVIEW}

This section to review main aspects in construction management have been applied machine learning techniques as follows:

\section{A. Assessing and reducing construction project risks}

One of the most wonderful aspects of machine learning is its ability to predict dangers before they occur. This aids humans in identifying hazards and determining how to avoid issues. Machine learning may assist project stakeholders to decrease risk by identifying risks, measuring their impact, and using predictive analytics. Therefore, many studies were undertaken to apply machine learning to predict and assess risks of construction projects [8-18]. For example, the study of [13] used machine learning to address the soft-margin support vector machines for supervised machine learning classification using n-fold cross-validation. The finding was a classification equation that, given a project's detected and assessed risk, accurately predicts its constructability class.

In addition, the study of [14] used distributed computing and an expanded cloud model to assess not only the overall state of construction safety but also potential security issues based on information feedback. It is possible to understand the objective existence of hazards in the construction process, which has significant guiding relevance for the construction. Furthermore, the study of [16] presented the development of a machine learning model for delay risk assessment in tall building projects. In this study, the techniques such as K-Nearest Neighbors (KNN), Artificial Neural Networks (ANN), Support Vector Machines (SVM), and Ensemble methods were adopted to develop a dataset suitable for machine learning application. This finding could support construction professionals in project risk management of tall buildings.

\section{B. Safety management for construction sites}

In many countries, the building business is considered one of the most hazardous [19]. Hence, construction safety is a top priority on all job sites, and machine learning offers a high-tech solution to this problem. That is why applying machine learning in construction safety has been attracted numerous researches to date [8, 14, 19-28]. In the study [21], neural network and decision tree analyses were implemented to assess the unsafe act of not anchoring harnesses while working on a scaffold of 40 migrant workers, whereas, with an accident data from the Singapore construction industry, a neural network analysis was performed on a quantitative occupational safety and health management system audit [22].

In addition, the study of [29] used a data collection of highly featured qualities and categorical safety outcomes to create safety models using two state-of-the-art ML models, Random Forest (RF) and Stochastic Gradient Tree Boosting (SGTB). Because of the binary and physical nature of the input variables, these models can accurately predict injury type, energy type, and body part; provide reliable probabilistic forecasts of likely outcomes should an accident occur, and show great potential for integration with building information modeling and work packaging. Aside from that, the study of [20] created sensorbased safety management systems and breakthroughs in site safety management using BIM. Sensor technology, wireless communication, computer processing power, and advances in machine learning and computer vision, according to this study, are now allowing the development of sensor-based safety management systems. A network theory was also established by [28] to investigate the intricacy of the subway construction accident network (SCAN). It can help improve safety management on subway construction sites by limiting original accidents and preventing subsequent and derivative incidents.

\section{Cost estimation and prediction}

Managers use construction cost projections to reduce time risk assessments as part of their decision-making process. Machine learning techniques require adequate data set size to model and project costs [30]. Particularly, some machine learning techniques were adopted to estimate or predict costs of various project types such as building projects [31-41], highway projects [42-48], public projects [49-53], roadway projects [5459], water-related construction projects [60-62], road tunnel projects $[63,64]$, railway projects $[65,66]$, hydropower projects $[67,68]$, power plant and power projects [69].

The studies of $[35,70]$ established an estimation model using fuzzy mathematics, estimated the similarity nearness degree of the project to be estimated and the built project through comparison with typical engineering cases, and realized cost estimation using the principle of choosing the nearest, and the dynamic coefficient was used to correct estimation results. The study of [36] proposeds an upgraded BP neural network estimate model with GA optimization based on the learning process of the standard BP neural network to determine investment and cost estimation scientifically and simplify investment estimating preparation. In addition, the study of [37] evaluated cost estimation of residential buildings using multifactor linear regression and advocated comparing the results with those 
Tam \& Toan / Journal of Applied Science and Technology Trends Vol. 02, No. 03, pp. 96 -104, (2021)

studies that used neural network techniques to see the differences.

The Back-Propagation Artificial Neural Network (BPANN) was used in a study by [38] to anticipate the cost of building projects in Nigeria; however, the model can only be used to institutional buildings; no other types of structures or projects can be evaluated using this method. Meanwhile, an artificial neural network was used to estimate structural costs for construction projects [71-74]. A combination of genetic algorithm and neural network in the construction cost estimate was developed by [75], while, [76] combined case-based reasoning with genetic algorithm optimization for preliminary cost estimation in the construction industry. Using pre-project planning factors, a hybrid principal component analysis and support vector machine model for predicting the cost performance of commercial building projects was developed in the study [77]. Meanwhile, the study of [41] developed a model that combines an unsupervised deep Boltzmann machine (DBM) learning strategy with a softmax layer (DBM-SoftMax), as well as a three-layer back-propagation neural network (BPNN) or another regression model, support vector machine (SVM). Construction cost data for 372 low- and midrise structures ranging from three to nine stories were used to validate this model. The suggested model's cost estimation errors were significantly lower than those of both the BPNNonly and SVM-only models, confirming the efficacy of the research methodologies and the proposed model's superiority.

\section{Construction schedule management}

It is often believed that the quality of early-stage planning will have a substantial impact on the project's final outcome [74]. Develop an innovative schedule-learning platform that integrates data science and machine learning to thousands of historic project schedules to better project management. This could be a one-of-a-kind and scalable approach for increasing project planning reliability and confidence. The study of [74] applied machine learning to construct artificial neural networks ensemble and support vector machines classification models to forecast project cost and schedule success, with early planning status as model inputs. In the study [78], through the use of statistical data and machine learning algorithms, a specific construction project was examined in order to identify the major causes of construction delays. The use of a predictive data mining model to assess the residual value of heavy construction equipment and its potential benefits for decision-making in the management of construction equipment has been introduced. The proposed approach has the advantages of ease of use, greater interpretability, and adequate accuracy when compared to the current practice of analyzing residual values for equipment [78].

\section{E. Building energy consumption forecasting}

Smart technology advancements have made it possible to forecast long- to medium-term electricity use in residential and commercial structures even before they are built. The building schedule and equipment information essential for forecasting are only available to indigenous information modeling systems on a limited basis [1]. The study of [79] investigated two newly developed stochastic models for forecasting energy consumption in time series, namely Conditional Restricted
Boltzmann Machine (CRBM) and Factored Conditional Restricted Boltzmann Machine (FCRBM). The evaluation is based on a benchmark data set that includes nearly four years of one-minute resolution electrical energy usage data collected from individual home users. For the energy prediction challenges answered here, FCRBM outperforms ANN, Support Vector Machine (SVM), Recurrent Neural Networks (RNN), and CRBM.

The study of [80] presented a recurrent neural network model to make medium-to long-term forecasts (i.e., the time horizon of the week, of one-hour electricity consumption profiles in commercial and residential buildings). The goal of this study was to construct and optimize novel deep recurrent neural network (RNN) models for medium to long-term electric load prediction at a one-hour resolution, as well as to compare the model's performance for different types of electricity consumption patterns. The deep RNN was then used to do imputation on a power consumption dataset with missing values segments. The study of [81] investigated how the deep-recurring neural network model predicts heating demand for campus buildings at the University of Utah over a period of weeks. The researchers then created an optimization methodology that could provide conclusive advice on the size of a stratified thermal storage tank without requiring high-performance computational resources.

\section{METHOD}

This study conducted a scientometric review, analysis and visualization to achieve the predefined research objectives of providing academics and industry practitioners with an in-depth understanding of the structure, research areas and trends in machine learning in construction management with illustrative diagrams and maps. The scientometric analysis is a technique that uses mathematical formulas and visualization to discover structural patterns and trace major research boundaries, allowing for a more comprehensive yet concise capture and mapping of scientific knowledge [82, 83]. Several authors have used this approach across research areas such as green building [84, 85], system dynamics applications [86], building information modeling [87], public-private partnership [88], and sustainability [82, 89].

In this study, bibliographic data collected from Scopus because this database has a wider range of scientific publication coverage compared to the Science, Dimensions, Google Scholar or Research Gate websites [90, 91]. Scopus also features a speedier indexing procedure, allowing for the retrieval of more recent papers $[84,88]$. Given the scope of machine learning in construction management, the search strategy in the Scopus database consists of two steps. First, "machine learning" or "neural network" or "optimization algorithm" and its synonyms are used to search for publications related to this domain. Second, "engineering," "construction," "project" and "management" are identified as the primary keywords for narrowing the subject related to this area. The result retrieved 253 scholarly articles. Then, the type of document is limited to "Article". The reason for this is that journal articles generally contain the highest quality research and their knowledge is considered to be "certified knowledge" in science mapping [85]. The length of time is set to all years. All the retrieved articles 
were carefully checked and only the articles published in journals were sorted out. Final, the abstracts of all the selected articles were reviewed and the articles in which the identification of adapting machine learning in construction management domain. As a consequence, a total number of 161 papers on machine learning in construction management were found and exported as full records and referenced in plain-text format, resulting in a dataset for this study. The research framework adopted is illustrated in Fig. 1.

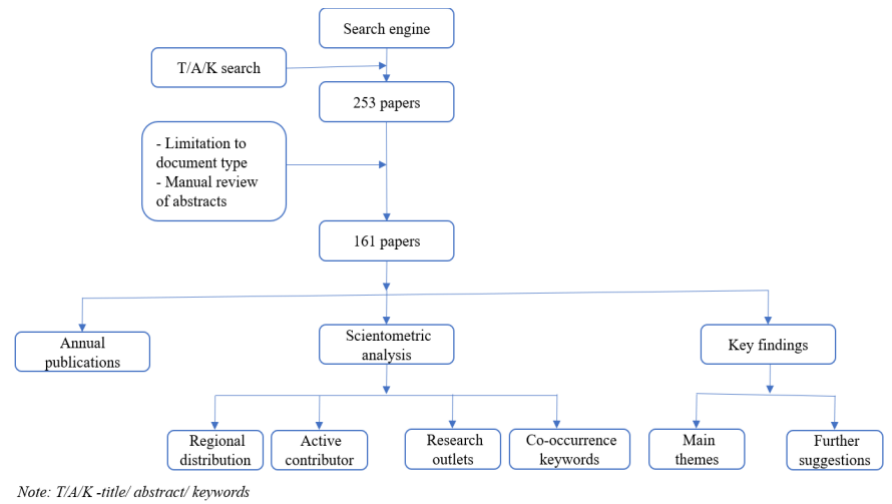

Fig. 1. Research framework for this study

\section{SCIENCE MAPPING RESUlts AND Discussions}

\section{A. Annual publications on machine learning in construction management}

The first publications on machine learning in construction management dated back to 1999 [92, 93]. In the study of [92], machine learning is used to automatically produce quadratic time-cost curves from historical data and to assess the credibility of each construction project's quadratic time-cost curve, whereas, the study of [93] looked explored how genetic algorithm techniques could be used to solve some of the optimization challenges in construction management and how they could help solve construction-related optimization difficulties.

The rise in publications corresponds to the global expansion of machine learning in construction management articles, as seen in Fig. 2. However, between 1999 and 2013, there was a minor increase in study machine learning in construction management; only a total of 19 studies were undertaken during these years. During the remainder of the observed time, however, there was a large increase in the number of publications on this topic. Particularly, in the period from 2014 to 2020,141 articles were published on machine learning in construction management. This proves the growth of interest in many researchers worldwide which can obviously foster more studies on this topic for implementing future researches.

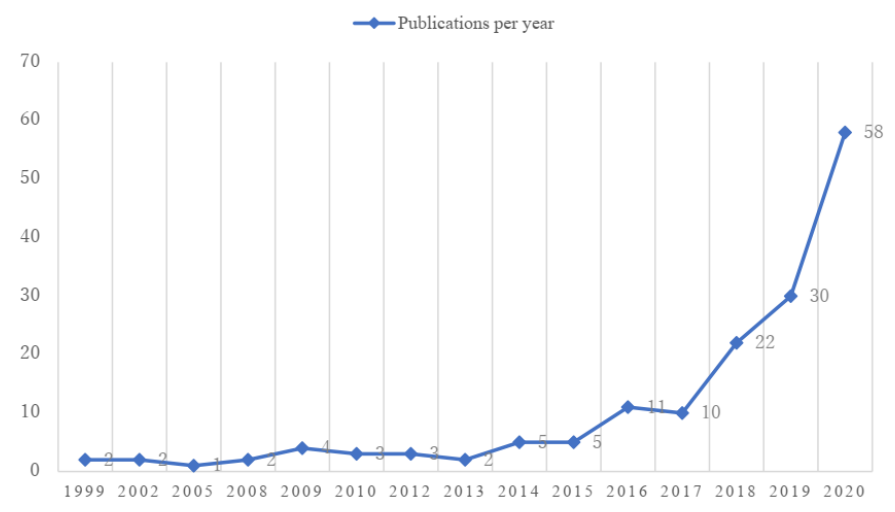

Fig. 2. Annual publication on machine learning in construction management

B. Geographical distribution of machine learning in construction management research

The contribution of the most productive countries (i.e., at least 4 publications on machine learning in construction management) is provided in Table 1. Accordingly, the United States, China, and Australia had the highest number of papers in this domain, accounting for 35,30 , and 15 , respectively. Setting the minimum number of nation papers and citations to 2 and 4 , respectively, produced Fig. 3. Of the 47 this topic research countries, 25 met the thresholds. Indeed, approximately $34 \%$ (46 out of 195) of all countries in the world are engaged in machine learning in construction management research.

TABLE I. MOST CONTRIBUTING COUNTRY/TERRITORY ON MACHINE LEARNING IN CONSTRUCTION MANAGEMENT RESEARCH

\begin{tabular}{|c|c|c|c|c|}
\hline Country & Documents & Citations & $\begin{array}{c}\text { Ave. } \\
\text { Citations }\end{array}$ & $\begin{array}{c}\text { Total link } \\
\text { strength }\end{array}$ \\
\hline United States & 35 & 846 & 24.17 & 6038 \\
\hline China & 30 & 606 & 20.20 & 4225 \\
\hline Australia & 15 & 357 & 23.80 & 4412 \\
\hline Hong Kong & 12 & 263 & 21.92 & 3496 \\
\hline $\begin{array}{c}\text { United } \\
\text { Kingdom }\end{array}$ & 10 & 213 & 21.30 & 3472 \\
\hline Canada & 6 & 244 & 40.67 & 1925 \\
\hline South Korea & 6 & 262 & 43.67 & 1580 \\
\hline Taiwan & 5 & 204 & 40.80 & 649 \\
\hline Germany & 4 & 134 & 33.50 & 2088 \\
\hline Viet Nam & 4 & 66 & 16.50 & 870 \\
\hline
\end{tabular}

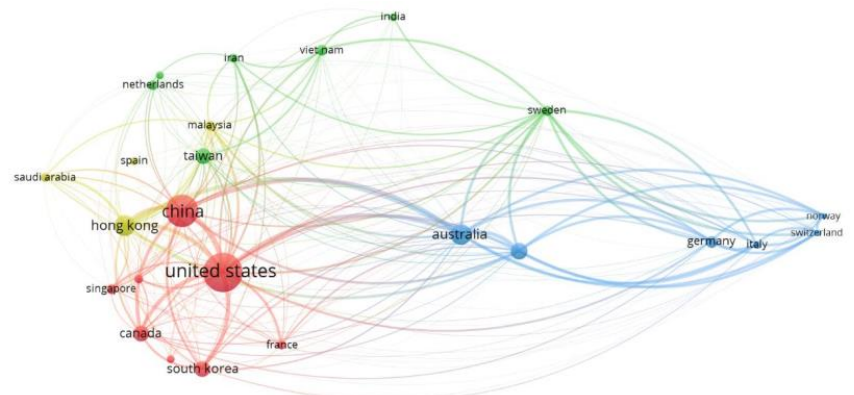

As vosviewer

Fig. 3. Country/territory distribution of on machine learning in construction management research 
Besides, it should be noted that the United States' node was the largest, implying that American experts were the primary contributors to research on this topic. Furthermore, despite of the fact that Hong Kong and Taiwan have small land areas, researchers from these territories received high average publications (12 and 5, respectively) and normalized citations (29.2 and 40.8, respectively), indicating that scholars from these two territories were highly competitive and made significant contributions to this domain.

\section{Author's contribution to machine learning in construction management}

According to literature retrieved from Scopus, the bibliographic coupling network of researchers on machine learning in construction management indicated that among 593 participated authors 57 researchers published more than 2 publications on this domain.

The topmost productive authors (i.e., 10 researchers who published at least 3 publications) studying machine learning in construction management were illustrated in Table 2. Li, H. tied for first place with 9 publications cited 187 times, representing normalized citations was 20.87 . Followed by Cheng, M.Y. and $\mathrm{Wu}, \mathrm{Y} . \mathrm{W}$. with the 6 and 5 publications, in turn. Those top productive researchers accounted for nearly $78 \%$ of the total volume of published documents on machine learning in construction management with 3195 times citations.

TABLE II. AUTHORS WITH HIGHEST PUBLICATIONS ON MACHINE LEARNING IN CONSTRUCTION MANAGEMENT

\begin{tabular}{|c|c|c|c|c|}
\hline Author & Documents & Citations & $\begin{array}{c}\text { Ave. } \\
\text { Citations }\end{array}$ & $\begin{array}{c}\text { Total link } \\
\text { strength }\end{array}$ \\
\hline Li, H. & 9 & 187 & 20.78 & 1098 \\
\hline Cheng, M.Y. & 6 & 234 & 39.00 & 361 \\
\hline Wu, Y.W. & 5 & 211 & 42.20 & 255 \\
\hline Rashidi, A. & 4 & 94 & 23.50 & 519 \\
\hline Zhang, M. & 4 & 22 & 5.50 & 143 \\
\hline Zhang, J. & 4 & 5 & 1.25 & 55 \\
\hline $\begin{array}{c}\text { Antwi-Afari, } \\
\text { M.F. }\end{array}$ & 3 & 17 & 5.67 & 109 \\
\hline Akhavian, R. & 3 & 99 & 33.00 & 283 \\
\hline Yu, Y. & 3 & 28 & 9.33 & 657 \\
\hline Cho, Y.K. & 3 & 70 & 23.33 & 129 \\
\hline
\end{tabular}

\section{Science mapping of academic journals}

In this section, the scientometric research discovered journal sources that publish machine learning in construction management. When the minimal number of documents and citations for a journal was set at three and ten, respectively, 17 out of 85 journals or proceedings matched the criteria.

According to the node and font sizes displayed in Fig. 5, Automation in Construction, Journal of Computing in Civil Engineering, and Journal of Construction Engineering and Management were among the most influential journals that had been contributing to the research community of machine learning in construction management. This finding was further supported by the statistics in Table 3, there were 25 articles published in the Automation in Construction had an outstanding performance, receiving the publications (25) and citations (557), occupying the first position in this topic research. Followed by the Journal of Computing in Civil Engineering with 14 papers (86 citations) and the Journal of Construction Engineering and
Management with 12 papers (176 citations) on this domain. Other most influential journals in this research domain included but were not limited to Applied Sciences Switzerland, IEEE Access, Journal of Building Engineering, Sensors Switzerland, Construction Innovation, Journal of Civil Engineering and Management, and Safety Science.

TABLE III. MOST PRODUCTIVE JOURNALS PUBLICATIONS

\begin{tabular}{|c|c|c|c|c|}
\hline Journal & Documents & Citations & $\begin{array}{c}\text { Ave. } \\
\text { Citations }\end{array}$ & $\begin{array}{c}\text { Total link } \\
\text { strength }\end{array}$ \\
\hline $\begin{array}{c}\text { Automation in } \\
\text { Construction }\end{array}$ & 25 & 557 & 22.28 & 388 \\
\hline $\begin{array}{c}\text { Journal of } \\
\text { Computing in } \\
\text { Civil Engineering }\end{array}$ & 14 & 486 & 34.71 & 147 \\
\hline $\begin{array}{c}\text { Journal of } \\
\text { Construction } \\
\text { Engineering and } \\
\text { Management }\end{array}$ & 12 & 176 & 14.67 & 336 \\
\hline $\begin{array}{c}\text { Applied Sciences } \\
\text { Switzerland }\end{array}$ & 9 & 59 & 6.56 & 132 \\
\hline \begin{tabular}{c} 
IEEE Access \\
\hline $\begin{array}{c}\text { Journal of } \\
\text { Building } \\
\text { Engineering }\end{array}$
\end{tabular} & 5 & 12 & 2.40 & 191 \\
\hline $\begin{array}{c}\text { Sensors } \\
\text { Switzerland }\end{array}$ & 5 & 27 & 5.40 & 30 \\
\hline $\begin{array}{c}\text { Construction } \\
\text { Innovation }\end{array}$ & 4 & 48 & 12.00 & 59 \\
\hline $\begin{array}{c}\text { Journal of Civil } \\
\text { Engineering and } \\
\text { Management }\end{array}$ & 4 & 42 & 10.50 & 37 \\
\hline $\begin{array}{c}\text { Safety Science } \\
\text { Safy }\end{array}$ & 4 & 68 & 17.00 & 10 \\
\hline
\end{tabular}

\section{E. Co-occurrence network of keyword}

Keyword analysis provides an opportunity to discover key research areas [94]. A network of keywords that co-occur in the documents and reflect the research papers' themes [95]. It also gives a good image of the knowledge domain, as well as insight into the topics addressed and how they are linked and arranged cognitively [96]. On the basis of the bibliographic data acquired from Scopus, the keywords co-occurrence network was created using the VOSviewer program. Author keywords were chosen instead of all keywords to create a replicable and comprehensible representation of keywords.

The 161 papers contain a total of 2071 keywords, according to the fractional counting methodology, and the minimum number of keyword occurrences was set at 5 to avoid the visualization of less relevant keywords. Only 78 keywords were found to match the criteria and were visualized. The number of articles in which the keywords appear together, demonstrating the association of their respective research areas, is used to compute the strength of the link between the two keywords; the stronger the link, the thicker the line that depicts the link in the network visualization [97].

It is clear that "machine learning" was the most popular study topic, indicating that this term was frequently utilized in this discipline. In addition, Table IV shows the information of terms that appeared often in the 161 evaluated papers. We can see that "learning systems," "project management," "artificial 
intelligence," and "construction industry" were all included in the popular research topics based on the keyword occurrences. Researchers should be aware of the most popular keywords so that they can choose the best keywords to utilize in their publications, allowing for easier indexing and retrieval.

TABLE IV. MOST ACTIVE KEYWORDS IN PUBLICATIONS ON MACHINE LEARNING IN CONSTRUCTION MANAGEMENT

\begin{tabular}{|l|c|c|}
\hline \multicolumn{1}{|c|}{ Keyword } & Occurrences & Total link strength \\
\hline Machine learning & 84 & 747 \\
\hline Learning systems & 77 & 680 \\
\hline Project management & 61 & 235 \\
\hline Artificial intelligence & 53 & 455 \\
\hline Construction industry & 48 & 337 \\
\hline Learning algorithms & 45 & 355 \\
\hline Support vector machines & 35 & 299 \\
\hline Forecasting & 34 & 264 \\
\hline Classification (of information) & 27 & 234 \\
\hline Deep learning & 27 & 199 \\
\hline Decision trees & 25 & 230 \\
\hline Neural networks & 24 & 169 \\
\hline Architectural design & 20 & 134 \\
\hline Construction equipment & 19 & 161 \\
\hline Supervised learning & 18 & 164 \\
\hline Construction project & 17 & 150 \\
\hline Data mining & 17 & 141 \\
\hline Construction & 17 & 130 \\
\hline Regression analysis & 16 & 109 \\
\hline Machine learning models & 15 & 126 \\
\hline
\end{tabular}

\section{SUGGESTION FOR FURTHER RESEARCH}

The massive amount of data regularly created by small and large construction enterprises presents prospects that the construction industry has yet to explore, as machine learning solutions for construction project management are still in their infancy. This section will discuss possible approaches to machine learning for future research.

\section{A. Increasing construction project life cycle}

Machine learning can be used in facility management to extend the asset's whole life cycle, in addition to design and construction. In general, crucial information in facility management is frequently missing. As a result, quickly and costeffectively managing on-site repairs and upgrades is tough. By gathering and making better use of data and information, machine learning can help to streamline the process. This can be accomplished by classifying documents and data as work orders and assessing the appropriate circumstances with startling precision in real-time. This relieves people of these tedious and time-consuming administrative tasks, allowing them to concentrate on the essential issue at hand. Machine learning can help predict the optimum way to undertake maintenance and repairs by envisioning when and where problems may develop if it is integrated into the BIM model in operation and maintenance.

\section{B. Improving quality management of design phrase}

Machine learning has the potential to improve overall designs in order to make environments better for their final human users. For instance, if clients want their living spaces to reflect how people use them. The organization was able to create a facility that best matches its needs before starting construction by using machine learning to better analyze and predict the frequency of use for these meeting rooms. The advantages of machine learning in design are endless. Machine learning can also assist workers in identifying potential design flaws and omissions prior to construction. Instead, they may rely on machine learning, which will save teams valuable time that can be better spent on more productive duties. They can also use machine learning to test different environmental conditions and situations in the model.

\section{Building energy efficiency retrofits}

The Building Performance Simulation system has been successfully integrated into the building design process, resulting in a considerable reduction in building energy usage. However, the industry still requires a retrofitting specialist who can advise on which building components should be removed or replaced in order to save money on energy. Machine learning algorithms can be used to recognize and classify building components, after which the likely contribution of each component can be predicted. These contributions should be compared to those of other components to see if replacing them would result in greater energy savings [98].

\section{CONCLUSIONS AND LiMITATIONS}

This study was conducted with the overarching goal of advocating for more research into areas where machine learning technology could be used in the field of building project management. To produce a comprehensive evaluation, a bibliometric search of journal articles, a scientometric analysis, and a qualitative discussion were undertaken in accordance with the defined scope of the literature review. This study used VOSviewer software to visualize a picture of the current status of this topic in five aspects, namely annual publications, regional publications, author's contribution, published journals, cooccurring keywords. Since 2014, the number of papers on machine learning in construction management has increased significantly, according to this study. Through regional study, researchers from the United States, China, and Australia have been the most significant contributors to this research area.

In the aspect of published journals, Automation in Construction received the highest publications and citations in this domain of research. The keywords of co-occurrence analysis, "machine learning," "learning systems," "project management," "artificial intelligence," and "construction industry" were the most popular keywords in this field. This papers also indicated that machine learning techniques have been applied in five popular aspects in construction project management domain, namely, assess and reduce risk, safety management for construction sites, cost estimation and prediction, Schedule management, and building energy demand prediction.

Both project stakeholders and academic researchers will benefit from this research. This review provides academics, graduate students, stakeholders, industry, government, energy policymakers, journals, and funding organizations with complete background information on machine learning in construction management. Graduate students and academics alike could look into the research gaps identified in the report. Stakeholders could utilize this data to help them make decisions. 
The main limitation of this study is that the use of certain keywords to retrieve publications from machine learning in construction management does not include all potential terms. Thus, the findings of the research may not fully reflect the entire literature available in this field. Furthermore, keywords may be reliable as a result of changing society and beliefs, which may cause some concepts to have different connotations. This study also used a Scopus dataset, therefore any limitations in Scopus coverage in publications could have an impact on the quality of the data used. When interpreting the findings, keep in mind the study's limitations. Future studies should be conducted on a regular basis to address the limits of using data from a range of sources, search algorithms, and indicators.

\section{REFERENCES}

[1] Akinosho, T.D., et al., Deep learning in the construction industry: A review of present status and future innovations. Journal of Building Engineering, 2020: p. 101827.

[2] Thompson, N., et al., Digitalisation in Construction-Industrial Strategy Review, supporting the Government's Industrial Strategy. University College London, London, 2017.

[3] Van Tam, N., et al., Impact of BIM-related factors affecting construction project performance. International Journal of Building Pathology and Adaptation, 2021. ahead-of-print(ahead-of-print) https://doi.org/10.1108/IJBPA-05-2021-0068

[4] Van Tam, N., N.L. Huong, and N.B. Ngoc, Factors affecting labour productivity of construction worker on construction site: A case of Hanoi. Journal of Science and Technology in Civil Engineering (STCE)-NUCE, 2018. 12(5): p. 127-138. https://doi.org/10.31814/stce.nuce2018-12(5)13

[5] Van Tam, N., et al., Factors affecting adoption of building information modeling in construction projects: A case of Vietnam. Cogent Business \& Management, 2021. 8(1): p. https://doi.org/10.1080/23311975.2021.1918848

[6] Lund, D., et al., Worldwide and regional internet of things (iot) 20142020 forecast: A virtuous circle of proven value and demand. International Data Corporation (IDC), Tech. Rep, 2014. 1(1): p. 9.

[7] Hegde, J. and B. Rokseth, Applications of machine learning methods for engineering risk assessment-A review. Safety science, 2020. 122: p. 104492.

[8] Ajayi, A., et al., Deep Learning Models for Health and Safety Risk Prediction in Power Infrastructure Projects. Risk Analysis, 2020. 40(10): p. 2019-2039.

[9] Antwi-Afari, M.F., et al., Construction Activity Recognition and Ergonomic Risk Assessment Using a Wearable Insole Pressure System. Journal of Construction Engineering and Management, 2020. 146(7).

[10] Fan, C.L., Defect Risk Assessment Using a Hybrid Machine Learning Method. Journal of Construction Engineering and Management, 2020. 146(9).

[11] Gondia, A., et al., Machine Learning Algorithms for Construction Projects Delay Risk Prediction. Journal of Construction Engineering and Management, 2020. 146(1).

[12] Hsu, M.F., Integrated multiple-attribute decision making and kernelbased mechanism for risk analysis and evaluation. Journal of Intelligent and Fuzzy Systems, 2019. 36(3): p. 2895-2905.

[13] Kifokeris, D. and Y. Xenidis, Risk source-based constructability appraisal using supervised machine learning. Automation in Construction, 2019. 104: p. 341-359.

[14] Liu, H. and G. Tian, Building engineering safety risk assessment and early warning mechanism construction based on distributed machine learning algorithm. Safety Science, 2019. 120: p. 764-771.

[15] Nasir, M., et al., A comparative data analytic approach to construct a risk trade-off for cardiac patients' re-admissions. Industrial Management and Data Systems, 2019. 119(1): p. 189-209.
[16] Sanni-Anibire, M.O., R.M. Zin, and S.O. Olatunji, Machine learning model for delay risk assessment in tall building projects. International Journal of Construction Management, 2020.

[17] Wang, F., et al., Modeling tunnel construction risk dynamics: Addressing the production versus protection problem. Safety Science, 2016. 87: p. 101-115.

[18] Yang, B., Construction of logistics financial security risk ontology model based on risk association and machine learning. Safety Science, 2020. 123.

[19] Poh, C.Q., C.U. Ubeynarayana, and Y.M. Goh, Safety leading indicators for construction sites: A machine learning approach. Automation in construction, 2018. 93: p. 375-386.

[20] Asadzadeh, A., et al., Sensor-based safety management. Automation in Construction, 2020. 113.

[21] Goh, Y.M. and N.F. Binte Sa'adon, Cognitive factors influencing safety behavior at height: a multimethod exploratory study. Journal of Construction Engineering and Management, 2015. 141(6): p. 04015003.

[22] Goh, Y.M. and D. Chua, Neural network analysis of construction safety management systems: a case study in Singapore. Construction Management and Economics, 2013. 31(5): p. 460-470.

[23] Gong, P., et al., Safety risk evaluations of deep foundation construction schemes based on imbalanced data sets. Journal of Civil Engineering and Management, 2020. 26(4): p. 380-395.

[24] Harirchian, E., et al., A machine learning framework for assessing seismic hazard safety of reinforced concrete buildings. Applied Sciences (Switzerland), 2020. 10(20): p. 1-18.

[25] Hou, L., et al., Deep learning-based applications for safety management in the AEC industry: A review. Applied Sciences (Switzerland), 2021. 11(2): p. 1-18.

[26] Lee, S.H. and J. Son, Development of a safety management system tracking the weight of heavy objects carried by construction workers using fsr sensors. Applied Sciences (Switzerland), 2021. 11(4): p. 1-15.

[27] Seong, H., H. Son, and C. Kim, A Comparative Study of Machine Learning Classification for Color-based Safety Vest Detection on Construction-Site Images. KSCE Journal of Civil Engineering, 2018. 22(11): p. 4254-4262.

[28] Zhou, Z., J. Irizarry, and Q. Li, Using network theory to explore the complexit of subway construction accident network (SCAN) for promoting safety management. Safety Science, 2014. 64: p. 127-136.

[29] Tixier, A.J.-P., et al., Application of machine learning to construction injury prediction. Automation in construction, 2016. 69: p. 102-114.

[30] Hashemi, S.T., O.M. Ebadati, and H. Kaur, Cost estimation and prediction in construction projects: A systematic review on machine learning techniques. SN Applied Sciences, 2020. 2(10): p. 1-27.

[31] Ji, S.-H., et al., Cost estimation model using modified parameters for construction projects. Advances in Civil Engineering, 2019. 2019.

[32] Khalaf, T.Z., et al., Particle swarm optimization based approach for estimation of costs and duration of construction projects. Civil Engineering Journal, 2020. 6(2): p. 384-401.

[33] Jiang, Q., Estimation of construction project building cost by backpropagation neural network. Journal of Engineering, Design and Technology, 2019.

[34] Chandanshive, V. and A.R. Kambekar, Estimation of building construction cost using artificial neural networks. Journal of Soft Computing in Civil Engineering, 2019. 3(1): p. 91-107.

[35] Wang, X., Application of fuzzy math in cost estimation of construction project. Journal of Discrete Mathematical Sciences and Cryptography, 2017. 20(4): p. 805-816.

[36] Du, Z. and B. Li. Construction project cost estimation based on improved BP Neural Network. in 2017 International Conference on Smart Grid and Electrical Automation (ICSGEA). 2017. IEEE.

[37] Alshemosi, A.M.B. and H.S.H. Alsaad, Cost estimation process for construction residential projects by using multifactor linear regression technique. Int J Sci Res, 2017. 6(6): p. 151-156.

[38] Bala, K., S.A. Bustani, and B.S. Waziri, A computer-based cost prediction model for institutional building projects in Nigeria. Journal of Engineering, Design and Technology, 2014. 
[39] He, X., et al. Cost estimation of construction project using fuzzy neural network model embedded with modified particle optimizer. in Advanced materials research. 2011. Trans Tech Publ.

[40] Arafa, M. and M. Alqedra, Early stage cost estimation of buildings construction projects using artificial neural networks. Journal of Artificial Intelligence, 2011. 4(1).

[41] Rafiei, M.H. and H. Adeli, Novel machine-learning model for estimating construction costs considering economic variables and indexes. Journal of construction engineering and management, 2018. 144(12): p. 04018106.

[42] Hegazy, T. and A. Ayed, Neural network model for parametric cost estimation of highway projects. Journal of construction engineering and management, 1998. 124(3): p. 210-218.

[43] Mahalakshmi, G. and C. Rajasekaran, Early cost estimation of highway projects in India using artificial neural network, in Sustainable construction and building materials. 2019, Springer. p. 659-672.

[44] Kim, S., Hybrid forecasting system based on case-based reasoning and analytic hierarchy process for cost estimation. Journal of Civil Engineering and Management, 2013. 19(1): p. 86-96.

[45] Chou, J.-S., Generalized linear model-based expert system for estimating the cost of transportation projects. Expert Systems with Applications, 2009. 36(3): p. 4253-4267.

[46] Shahandashti, S. and B. Ashuri, Highway construction cost forecasting using vector error correction models. Journal of management in engineering, 2016. 32(2): p. 04015040.

[47] Wilmot, C.G. and B. Mei, Neural network modeling of highway construction costs. Journal of construction engineering and management, 2005. 131(7): p. 765-771

[48] Sodikov, J., Cost estimation of highway projects in developing countries: artificial neural network approach. Journal of the Eastern Asia Society for Transportation Studies, 2005. 6: p. 1036-1047.

[49] Alshamrani, O.S., Construction cost prediction model for conventional and sustainable college buildings in North America. Journal of Taibah University for Science, 2017. 11(2): p. 315-323.

[50] Hyari, K.H., A. Al-Daraiseh, and M. El-Mashaleh, Conceptual cost estimation model for engineering services in public construction projects. Journal of Management in Engineering, 2016. 32(1): p. 04015021.

[51] Yu, W.D., PIREM: a new model for conceptual cost estimation. Construction management and economics, 2006. 24(3): p. 259-270.

[52] Skitmore, R.M. and S.T. Ng, Forecast models for actual construction time and cost. Building and environment, 2003. 38(8): p. 1075-1083.

[53] Bowen, P. and P. Edwards, Cost modelling and price forecasting: practice and theory in perspective. Construction Management and Economics, 1985. 3(3): p. 199-215.

[54] Tijanić, K., D. Car-Pušić, and M. Šperac, Cost estimation in road construction using artificial neural network. Neural Computing and Applications, 2019: p. 1-13.

[55] Swei, O., J. Gregory, and R. Kirchain, Construction cost estimation: A parametric approach for better estimates of expected cost and variation. Transportation Research Part B: Methodological, 2017. 101: p. 295-305.

[56] Peško, I., et al., Estimation of costs and durations of construction of urban roads using ANN and SVM. Complexity, 2017. 2017.

[57] Chou, J.-S., Cost simulation in an item-based project involving construction engineering and management. International Journal of Project Management, 2011. 29(6): p. 706-717.

[58] Kim, K.J. and K. Kim, Preliminary cost estimation model using casebased reasoning and genetic algorithms. Journal of Computing in Civil Engineering, 2010. 24(6): p. 499-505.

[59] Bouabaz, M. and M. Hamami, A cost estimation model for repair bridges based on artificial neural network. American Journal of Applied Sciences, 2008. 5(4): p. 334-339.

[60] Marzouk, M. and M. Elkadi, Estimating water treatment plants costs using factor analysis and artificial neural networks. Journal of Cleaner Production, 2016. 112: p. 4540-4549.

[61] Ahiaga-Dagbui, D.D. and S.D. Smith, Neural networks for modelling the final target cost of water projects. 2012.

[62] Alex, D.P., et al., Artificial neural network model for cost estimation: City of Edmonton's water and sewer installation services. Journal of construction engineering and management, 2010. 136(7): p. 745-756.

[63] Petroutsatou, K., et al., Early cost estimating of road tunnel construction using neural networks. Journal of construction engineering and management, 2012. 138(6): p. 679-687.

[64] Petroutsatou, K. and S. Lambropoulos, Road tunnels construction cost estimation: a structural equation model development and comparison. Operational Research, 2010. 10(2): p. 163-173.

[65] Gunduz, M., L.O. Ugur, and E. Ozturk, Parametric cost estimation system for light rail transit and metro trackworks. Expert Systems with Applications, 2011. 38(3): p. 2873-2877.

[66] Kim, B.S., The approximate cost estimating model for railway bridge project in the planning phase using CBR method. KSCE Journal of Civil Engineering, 2011. 15(7): p. 1149.

[67] Singal, S., R. Saini, and C. Raghuvanshi, Analysis for cost estimation of low head run-of-river small hydropower schemes. Energy for sustainable Development, 2010. 14(2): p. 117-126.

[68] Gunduz, M. and H.B. Sahin, An early cost estimation model for hydroelectric power plant projects using neural networks and multiple regression analysis. Journal of Civil Engineering and Management, 2015. 21(4): p. 470-477.

[69] Hashemi, S.T. and H. Kaur, A hybrid conceptual cost estimating model using ANN and GA for power plant projects. Neural Computing and Applications, 2019. 31(7): p. 2143-2154.

[70] El-Sawalhi, N.I., Modelling the parametric construction project cost estimate using fuzzy logic. International Journal of Emerging Technology and Advanced Engineering Website:(ISSN 2250-2459, Volume 2, Issue 4, 2012. 2(4).

[71] El-Sawalhi, N.I. and O. Shehatto, A neural network model for building construction projects cost estimating. Journal of Construction Engineering and Project Management, 2014. 4(4): p. 9-16.

[72] Roxas, C.L.C. and J.M.C. Ongpeng. An artificial neural network approach to structural cost estimation of building projects in the Philippines. in Proc. DLSU Research Congress. 2014.

[73] Jafarzadeh, R., et al., Application of artificial neural network methodology for predicting seismic retrofit construction costs. Journal of Construction Engineering and Management, 2014. 140(2): p. 04013044.

[74] Wang, Y.-R., C.-Y. Yu, and H.-H. Chan, Predicting construction cost and schedule success using artificial neural networks ensemble and support vector machines classification models. International Journal of Project Management, 2012. 30(4): p. 470-478.

[75] Feng, G.L. and L. Li. Application of genetic algorithm and neural network in construction cost estimate. in Advanced materials research. 2013. Trans Tech Publ.

[76] Kim, S. and J.H. Shim, Combining case-based reasoning with genetic algorithm optimization for preliminary cost estimation in construction industry. Canadian Journal of Civil Engineering, 2014. 41(1): p. 65-73.

[77] Son, H., C. Kim, and C. Kim, Hybrid principal component analysis and support vector machine model for predicting the cost performance of commercial building projects using pre-project planning variables. Automation in Construction, 2012. 27: p. 60-66.

[78] Kim, H., L. Soibelman, and F. Grobler, Factor selection for delay analysis using knowledge discovery in databases. Automation in Construction, 2008. 17(5): p. 550-560.

[79] Mocanu, E., et al., Deep learning for estimating building energy consumption. Sustainable Energy, Grids and Networks, 2016. 6: p. 91-99.

[80] Rahman, A., V. Srikumar, and A.D. Smith, Predicting electricity consumption for commercial and residential buildings using deep recurrent neural networks. Applied energy, 2018. 212: p. 372-385.

[81] Rahman, A. and A.D. Smith, Predicting heating demand and sizing a stratified thermal storage tank using deep learning algorithms. Applied Energy, 2018. 228: p. 108-121.

[82] Olawumi, T.O. and D.W. Chan, A scientometric review of global research on sustainability and sustainable development. Journal of cleaner production, 2018. 183: p. 231-250.

[83] Montoya, F.G., et al., The research on energy in Spain: A scientometric approach. Renewable and Sustainable Energy Reviews, 2014. 29: p. 173183. 
Tam \& Toan / Journal of Applied Science and Technology Trends Vol. 02, No. 03, pp. 96 -104, (2021)

[84] Darko, A., et al., A scientometric analysis and visualization of global green building research. Building and Environment, 2019. 149: p. 501511.

[85] Xiao, X., et al., Mapping knowledge in the economic areas of green building using scientometric analysis. Energies, 2019. 12(15): p. 3011.

[86] Wu, Z., et al., A scientometric review of system dynamics applications in construction management research. Sustainability, 2020. 12(18): p. 7474.

[87] Liu, Z., Y. Lu, and L.C. Peh, A review and scientometric analysis of global building information modeling (BIM) research in the architecture, engineering and construction (AEC) industry. Buildings, 2019. 9(10): p. 210.

[88] Van Tam, N., Scientometric Review of Research Trends on Public Private Partnership (PPP) for Infrastructure Projects From 2000 to 2020. 2021. Vol. 4. 2021. https://doi.org/10.32783/csid-jid.v4i1.215

[89] de Toledo, R.F., et al., A scientometric review of global research on sustainability and project management dataset. Data in brief, 2019. 25: p. 104312 .

[90] Zhao, X., et al., A bibliometric review of green building research 2000 2016. Architectural Science Review, 2019. 62(1): p. 74-88.

[91] Meho, L.I. and Y. Rogers, Citation counting, citation ranking, and $h$ index of human - computer interaction researchers: a comparison of
Scopus and Web of Science. Journal of the American Society for Information Science and Technology, 2008. 59(11): p. 1711-1726.

[92] Li, H., J.N. Cao, and P.E.D. Love, Using machine learning and GA to solve time-cost trade-off problems. Journal of Construction Engineering and Management, 1999. 125(5): p. 347-353.

[93] Al-Tabtabai, H. and A.P. Alex, Using genetic algorithms to solve optimization problems in construction. Engineering, Construction and Architectural Management, 1999. 6(2): p. 121-132.

[94] Shrivastava, R. and P. Mahajan, Artificial intelligence research in India: A scientometric analysis. Science \& Technology Libraries, 2016. 35(2): p. 136-151.

[95] Wuni, I.Y., G.Q. Shen, and R. Osei-Kyei, Scientometric review of global research trends on green buildings in construction journals from 1992 to 2018. Energy and buildings, 2019. 190: p. 69-85.

[96] Van Eck, N.J. and L. Waltman, Visualizing bibliometric networks, in Measuring scholarly impact. 2014, Springer. p. 285-320.

[97] Van Eck, N. and L. Waltman, Manual for VOSviewer version 1.6. 8. CWTS Meaningful Metrics. Universiteit Leiden, 2018.

[98] Akinosho, T.D., et al., Deep learning in the construction industry: A review of present status and future innovations. Journal of Building Engineering, 2020. 32. 